\title{
Commentary: Pursuit of the green jacket: Mastery of the long and short games
}

\author{
Daniel P. Raymond, MD
}

\author{
From the Center for Chest Wall Disease, Cleveland Clinic Foundation, Cleveland, Ohio. \\ Disclosures: Author has nothing to disclose with regard to commercial support. \\ Received for publication Oct 9, 2018; accepted for publication Oct 9, 2018; available ahead of print Nov 13, 2018. \\ Address for reprints: Daniel P. Raymond, MD, Cleveland Clinic Foundation, 9500 Euclid Ave, J4-1, Cleveland, \\ OH 44195 (E-mail: Raymond3@ccf.org). \\ J Thorac Cardiovasc Surg 2019;157:1644-5 \\ $0022-5223 / \$ 36.00$ \\ Copyright (c) 2018 by The American Association for Thoracic Surgery \\ https://doi.org/10.1016/j.jtcvs.2018.10.042
}

"Drives are for show and putting is for dough." I am no golfer, yet I am offered this axiom when consulting my colleagues down the hall about their beloved sport. Clearly, the message being conveyed is that the short game is the key to success. The converse may also be true, as highlighted by golfing legend Harvey Penick, "The woods are full of long drivers."

Fernandez and colleagues ${ }^{1}$ take a swing at the concept of the short-term versus long-term game in their article in this issue of the Journal, "Lack of Correlation Between Shortand Long-Term Performance Following Lung Cancer." One can see the approach to this article with the group's former publication, the J Maxwell Chamberlain Memorial Paper ${ }^{2}$ on prediction of long-term survival in elderly patients, which used Society of Thoracic Surgeons data linked to Medicare data (thus only patients older than 65 years). Fernandez and colleagues ${ }^{1}$ have used the same data set to assess the performance of programs with regard to their short and long games. They demonstrate no statistical correlation between short-term and long-term performance among programs. Furthermore, they note that there is not a single program that is a statistical outlier (or what the Society of Thoracic Surgeons would term a "three star" program) for both short and long games. Logically, the conclusion drawn is that the long-term game is currently neglected in quality measures. One can therefore foresee the suggestion of a unified scorecard that each program must sign.

One problem with the conclusions of Fernandez and colleagues ${ }^{1}$ is that surgical safety and oncologic quality are separate principles. Rather, surgical safety is a dimple on the golf ball of oncologic quality, yet it is the dimple over which surgeons claim the greatest domain. For instance, Wong and associates ${ }^{3}$ demonstrated in an evaluation of 9001 patients with surgically completely resected lung cancer randomly selected from the National Cancer Database, $20.5 \%$ of patients with locoregional recurrence and $22.7 \%$ of patients with distant recurrence received no treatment other than supportive care. Such decisions are made by

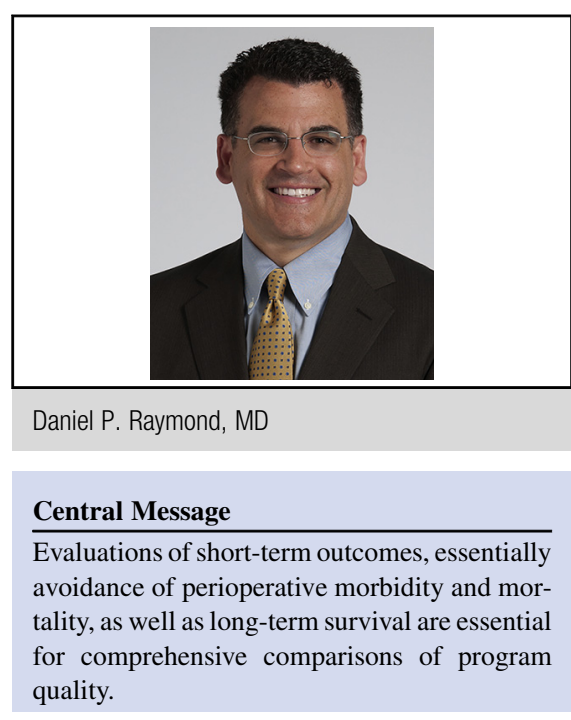

See Article page 1633.

medical and radiation oncologists, and long-term survival is thus often more a cancer system quality measure than a surgeon-specific measure. Dichotomizing surgical safety and oncologic quality furthermore ignores the wealth of information in the literature linking postoperative morbidity with long-term outcomes. In a retrospective analysis of 828 patient undergoing video-assisted thoracoscopic surgical lobectomy at Peking Hospital, Wang and colleagues ${ }^{4}$ noted that generic pulmonary complications were not determinant of long-term complications. On the other hand, major pulmonary complications (those graded as 3 or 4) were independent predictors of recurrence (hazard ratio, 1.93; $95 \%$ confidence interval, $1.3-2.87 ; P=.001$ ), as well as 3- and 5-year disease-free and overall survivals. Perhaps the lack of severity grading in the present Society of Thoracic Surgeons system obscures this relationship in the analysis of Fernandez and colleagues. ${ }^{1}$

As a spectator in the current match, I laud the accomplishments of Fernandez and colleagues. ${ }^{1}$ One can see their strategy as they advance to the next hole after demonstrating decisively on past holes their commitment to quality research that moves the pin in lung cancer care. On this hole, they have demonstrated that the long and short games both require consideration and mastery if one is to wear the green jacket. I look forward to the next hole and anticipate that, before the 18th, we will have a more comprehensive scorecard to assess the players in lung cancer care quality. 


\section{References}

1. Fernandez FG, Kosinski AS, Tong BC, Furnary AP, Feng L, Onaitis M, et al. Lack of correlation between short- and long-term performance after lung cancer surgery. J Thorac Cardiovasc Surg. 2019;157:1633-43.e3.

2. Onaitis MW, Furnary AP, Kosinski AS, Kim S, Boffa D, Tong BC, et al. Prediction of long-term survival after lung cancer surgery for elderly patients in the Society of Thoracic Surgeons General Thoracic Surgery Database. Ann Thorac Surg. 2018; 105:309-16.

3. Wong ML, McMurry TL, Stukenborg GJ, Francescatti AB, AmatoMartz C, Schumakcher JR, et al. Impact of age and comorbidity on treatment of non-small cell lung cancer recurrence following complete resection: a nationally representative cohort study. Lung Cancer. 2016; 102:108-17.

4. Wang S, Li X, Li Y, Li J, Jiang G, Liu J, et al. The long-term impact of postoperative pulmonary complications after video-assisted thoracic surgery lobectomy for lung cancer. J Thorac Dis. 2017;9:5143-52. 